\title{
Chagas disease: review of needs, neglect, and obstacles to treatment access in Latin America
}

\author{
Eloan Pinheiro[1], Lucia Brum-Soares ${ }^{[2]}$, Renata Reis ${ }^{[3]}$ \\ and Juan-Carlos Cubides ${ }^{[2]}$
}

\author{
[1]. Consultora em Saúde Pública, Rio de Janeiro, RJ, Brasil. \\ [2]. Unidade Médica Brasileira, Médicos Sem Fronteiras, Rio de Janeiro, RJ, Brasil. \\ [3]. Advocacy e Relações Interinstitucionais, Médicos Sem Fronteiras, Rio de Janeiro, RJ, Brasil.
}

\begin{abstract}
After more than one century since its discovery, Chagas disease is still extremely prevalent in 21 Latin American countries. Chagas disease is one of the most concerning public health problems in Latin America; the overall cost of CD treatment is approximately 7 billion United States dollars per year and it has a strong social impact on populations. Little progress has been made regarding the access to diagnosis and treatment at the primary health care level, calling into question the current policies to ensure the right to health and access to essential medications. In this article, diverse dimensions of access to treatment for Chagas disease are reviewed, illustrating the present state of benznidazole medication in relation to global production capacity, costs, and needs. The findings are based on an investigation requested by Médecins Sans Frontières Brazil through a consultancy in 2015, aiming to estimate the current costs of benznidazole production.
\end{abstract}

Keywords: Chagas Treatment. Benznidazole. Access. Latin America.

\section{INTRODUCTION}

Chagas disease (CD) has been around for more than one century ${ }^{1}$; however, it continues to be one of the most prevalent public health problems in Latin America to date ${ }^{2}$. Despite the right to health and access to essential medications, $\mathrm{CD}$ is a key example of the barriers to accessing primary health care (PHC) services.

Information on production costs in pharmaceutical industries is generally withheld. Decoding production costs for CD treatment may be useful for patients, managers, and governments to have adequate information for decision-making and advocacy planning to increase access to $\mathrm{CD}$ treatment with more precision. Given the lack of knowledge and information regarding the access to $\mathrm{CD}$ diagnosis and treatment, Médecins Sans Frontières (MSF) Brazil conducted an investigation in 2015 in collaboration with a consultant to better understand the global standards for the production of medication for the treatment of $\mathrm{CD}$, specifically benznidazole (BZN).

The investigation included interviews of laboratory staff and questionnaires sent to laboratories that manufacture the raw materials for the final BZN pill. From the information collected,

Corresponding author: MSc. Juan-Carlos Cubides.

e-mail: juan.cubides@rio.msf.org

Received 2 December 2016

Accepted 5 May 2017 an analysis model of cost appropriation was built based on the methodology proposed by Pinheiro et al., in $2006^{3}$. This model has already been validated by the World Health Organization (WHO) and has been used in previous studies by the consultancy agency, particularly those investigating the cost of antiretroviral drugs. The model is based on a fluxogram where the standard cost (or unitary production cost) is pre-determined and obtained through the detailed study of the use of raw materials, labor, equipment, and the sum of all procedures that make up the global process to manufacture one unit of the physical product. Thus, direct costs (depreciation of equipment, labor, formulation, packaging, and domestic transportation), indirect costs of production (overhead, administration, research, reinvestment, and general production costs), and profit margin are analyzed in the model ${ }^{3}$. In this review, findings from the model are highlighted in order to shed light on the factors affecting access to BZN in Latin America and particularly Brazil.

\section{OVERVIEW OF CHAGAS DISEASE IN THE AMERICAS}

The WHO estimates that globally there are approximately 6 million people infected with Trypanosoma cruzi, the protozoan that causes $\mathrm{CD}$, and furthermore, more than 70 million people are living in areas with high risk of CD transmission ${ }^{4}$. CD endemic areas include 21 countries in Latin America. Brazil, Mexico, Argentina, and Bolivia have the highest prevalence rates of infected people, accounting for approximately $71 \%$ (4.2 million) of the estimated cases $^{5}$. Bolivia has the greatest 
incidence of $\mathrm{CD} ; 60 \%$ of the national territory is considered an area of risk for vector transmission. In addition to being the leading killer among parasitic diseases, CD represents a significant economic burden to health care systems ${ }^{2,6}$.

There has been a significant reduction in the appearance of new cases through vector transmission due to control actions promoted by intergovernmental initiatives in the Americas for the past 30 years. However, $C D$ is still recognized as a neglected disease, which mainly affects vulnerable populations in urgent need of basic policies that promote access to health care.

Presently, the governments' absence or inefficiency in responding to $\mathrm{CD}$ involves various elements ranging from medical supply and training, to proper access to diagnosis and treatment. There is low investment and lack of interest from the private pharmaceutical sector on investigation towards the development of innovative tests and better medications, together with the absence of accurate epidemiological data on the disease (prevalence and incidence in endemic countries corresponds to outdated estimates). As indicated, there is an intricate net of obstacles that continue to contribute to the cycle of CD neglect.

In 2015 , it was estimated that more than $80 \%$ of the people in the world affected by $\mathrm{CD}$ did not have access to diagnosis and specific treatment. This historical negligence is a contributing factor to the increases in the morbidity and mortality as a result of $\mathrm{CD}$ as well as its social costs. Although treatment is not indicated for all cases, most of those chronically infected or presenting with a chronic indeterminate form of $\mathrm{CD}$ [all individuals with chronic infection by $T$. cruzi-with reactive serology that do not suggest clinical symptoms of $\mathrm{CD}$ due to normal electrocardiogram (ECG) readings, chest radiography, esophagus's, and colons] -should receive specific treatment in accordance with the indications detailed in the 2016 Brazilian consensus on $\mathrm{CD}^{7}$. The findings of the BENEFIT trial have highlighted that for clinically asymptomatic patients with established Chagas' cardiomyopathy, trypanocidal therapy did not significantly reduce cardiac clinical deterioration; however, it significantly reduced serum parasite detection ${ }^{8}$.

The WHO has established four fundamental pillars that must be observed and implemented for $\mathrm{CD}$ so that access to medication is ensured in adequate quantity, quality, location, and timing. Proper access to medicines can occur when the management process ensures a rational selection (based on proper lists of essential medications and protocols); affordable prices for governments, health services providers, and consumers; and the existence of reliable health and supply systems and sustainable financing for acquisition'. Unfortunately, CD programs in Latin America do not satisfactorily meet any of the pillars established by the WHO. There are critical problems such as low production capacity, inaccurate data to estimate the true demand, absence of inclusive policies for patients, and outdated technical guidelines to advise and regulate the performance of health professionals based on current knowledge.

\section{HISTORY OF CHAGAS DISEASE MEDICA- TION PRODUCTION}

Benznidazole and nifurtimox (NFX), the first- and secondline treatment for $\mathrm{CD}$, respectively, were made available in the market in the 70's, and to date, are the only two drugs available for the treatment of CD in the world. Unfortunately, the portfolio of investigated molecules with trypanosomicide potential is limited, diminishing the possibility of innovative treatments.

Benznidazole was originally produced by Roche under the names of Rochagan ${ }^{\circledR}$ and Radanil ${ }^{\circledR}$, and was registered in Argentina, Brazil, Bolivia, Uruguay, Peru, Nicaragua, and Japan. In April 2003, after Roche discontinued production and commercialization of BZN, fabrication technology and rights were transferred to the Brazilian government. Only in 2008, were the first batches of Brazilian BZN produced by the public Pharmaceutical Laboratory of the State of Pernambuco [Laboratório Farmacêutico de Pernambuco (LAFEPE)]; this BZN was still manufactured with residual raw material [Active Pharmaceutical Ingredient (API)] supplied by Roche. As it was necessary to produce API-BZN locally in order to ensure appropriate supply, the Brazilian Ministry of Health negotiated with LAFEPE to transfer production of the raw material to the local private company Nortec.

LAFEPE was the only BZN producer in the world until 2011, when the absence of the certification for Good Manufacturing Practices (GMP) for BZN production issued by the National Agency of Sanitary Vigilance [Agência Nacional de Vigilância Sanitária (ANVISA)] highlighted the impossibility of commercialization of the drug through the strategic Pan-American Health Organization (PAHO) fund, the main mechanism of acquisition for endemic countries. At that time, the private Argentinian laboratory Elea, also started manufacturing BZN. For its production, Elea uses the API-BZN from the private Argentinian laboratory named Maprimed. Both laboratories belong to the Chemo group. Elea then became the only producer of BZN able to commercialize use through the PAHO fund.

In line with the fundamental requirements established by the WHO, in order to ensure proper access to medication, a continuous and reliable supply system needs to be in place. Production monopolies will interfere with accessing the final product if these systems are not in place; therefore, it is crucial that there is more than one world producer to ensure that the medication gets to the patient, regardless of adverse external factors that may hinder the supply.

\section{CURRENT BENZNIDAZOLE PRODUCERS AND THEIR CAPACITY}

As outlined previously, there are two producers of API-BZN in Latin America (NORTEC and MAPRIMED) as well as two manufacturers of the final BZN product for commercial use (LAFEPE and ELEA).

NORTEC is located in Rio de Janeiro (Brazil) and is the biggest manufacturers of active pharmaceutical ingredients in Latin America. Currently registered and certified in GMP by ANVISA, it has a production capacity for API-BZN of $1,000 \mathrm{~kg}$ per campaign that could be expanded to reach a maximum of $2,000 \mathrm{~kg}$.

MAPRIMED is located in Buenos Aires (Argentina) and its API-BZN production is also registered and certified in GMP, by the National Administration on Medication, Food and Medical Technology (ANMAT). The laboratory production capacity is similar to that of NORTEC, producing $1,000 \mathrm{~kg}$ per campaign that could be expanded to a maximum of $2,000 \mathrm{~kg}$. 
LAFEPE manufactures 100 and $12.5 \mathrm{mg}$ BZN pills for adult and pediatric patients, respectively. Conversely, Elea manufactures 100 and 50mg BZN pills for adults and pediatric patients, respectively.

\section{CHAGAS DISEASE TREATMENT NEEDS}

The full course of $\mathrm{CD}$ treatment for an adult with an average weight of $70 \mathrm{~kg}$ requires approximately $180,100 \mathrm{mg}$ pills. In a regular treatment scheme, three pills are administered daily over a period of 60 days. Therefore, the full treatment course consists of a total of $18,000 \mathrm{mgs}$ of BZN (equivalent to $0.018 \mathrm{~kg}$ of API-BZN).

If deemed clinically well, patients infected with $\mathrm{CD}$ will not meet eligibility criteria for treatment ${ }^{10}$. However studies have proven that widening the indications for treatment, thus expanding access to treatment, are beneficial in successfully curing $\mathrm{CD}^{11}$; reducing or preventing the progression of disease ${ }^{11-13}$; and breaking the chain of transmission ${ }^{14,15}$, which has proven to be a safe and effective measure for primary disease prevention ${ }^{15,16}$. In the past three decades, a consensus has been reached that parasite persistence is crucial for the development and progression of Chagas cardiomyopathy ${ }^{8}$. Thus, it is imperative that access to treatment be expanded to greater numbers of patients. The current global API-BZN production capacity (4,000 $\mathrm{kg}$ maximum) is not adequate to deal with the $\mathrm{CD}$ treatment needs. Hence, the cycle of neglect and the failure to ensure the basic pillars regarding access to treatment are perpetuated.

\section{ESTIMATE OF BENZNIDAZOLE COSTS}

The estimates of the direct costs of BZN use (Table 1) were calculated in the model using the lowest [750 United States dollars (USD) as informed by NORTEC] and the highest (2,000USD estimated from market information, since MAPRIMED did not provide the sale value) API-BZN prices per kilogram. After overviewing the direct production costs, we determined that the API-BZN price had a strong impact on the overall BZN cost. In the case of BZN, the proportional cost of the raw active compound rose from $87 \%$ to $95 \%$ when different quotations for API-BZN per kilogram were used.
Additionally, the estimates of the final costs of BZN use were calculated for public and private laboratories (Table 2). Different values for general expenses were applied when comparing the public and private laboratory as the cost appropriation model for production is based on the principle that the public laboratory does not have the adequate structure for commercialization and international marketing in line with private sector's traditional standards and costs. As expected, variations were observed between the types of laboratories; additionally, there were significant increases in total cost when the price of API-BZN varied.

\section{COMPARISON OF MARKET PRICES AND COST ESTIMATES}

MSF acquires one BZN pill manufactured by LAFEPE for 0.2129USD while the PAHO pays 0.4751USD for one pill manufactured by the ELEA private laboratory. When comparing the estimated price values for private production versus the laboratory's market prices (Table 3), with the estimated cost of API-BZN as 750USD per kilogram, we found that LAFEPE charged $66.3 \%$ more than the final estimated price. Additionally, ELEA charged 271.2\% more that the final estimated price, which already included a $14 \%$ profit margin. Conversely, if we used the price estimate considering the highest API-BZN value (2,000USD per kilogram), LAFEPE's price was $32.05 \%$ less and ELEA's price was still $52.14 \%$ more than the estimated final price. The data ascertained from the model disavows the current belief that laboratories manufacturing BZN are subsidized or charge what is called a humanitarian price, just to cover costs. Again, we draw attention to the fact that the medication's price is linked to the variations in the API-BZN prices charged.

It is evidenced that both laboratories profit from the production and sale of BZN significantly above the $14 \%$ profit margin employed in these models. Although the expansion of access to BZN is not exclusively connected to price, it cannot be denied that costs affect people's access to treatment, especially in poor, undeveloped countries. We believe that the high prices charged by ELEA are related to the fact that for a long time the global production of BZN was monopolized by ELEA in the absence of a GMP certificate by LAFEPE, preventing its commercialization outside of Brazil. Presently, production is

TABLE 1

Estimated direct benznidazole production costs depending on final price variations in active pharmaceutical ingredient benznidazole.

\begin{tabular}{|c|c|c|c|c|c|c|}
\hline \multirow{2}{*}{ Item } & \multicolumn{3}{|c|}{$\begin{array}{c}\text { Lowest price API } \\
750 \mathrm{USD} / \mathrm{kg}\end{array}$} & \multicolumn{3}{|c|}{$\begin{array}{c}\text { Highest price API } \\
2,000 \mathrm{USD} / \mathrm{kg}\end{array}$} \\
\hline & unity & batch* & $\%$ & unity & batch* & $\%$ \\
\hline Equipment & 0,002854 & 1.427 & 3.0 & 0,002854 & 1.427 & 1.0 \\
\hline Labor & 0,002204 & 1.102 & 3.0 & 0,002204 & 1.102 & 1.0 \\
\hline API-benznidazole & 0,075 & 37.500 & 87.0 & 0,2 & 100.000 & 95.0 \\
\hline Ingredients/excipients & 0,00236 & 1.180 & 3.0 & 0,00236 & 1.180 & 1.0 \\
\hline Packaging & 0,00386 & 1930 & 4.0 & 0,00386 & 1930 & 2.0 \\
\hline Total direct cost & 0,086278 & 43.139 & 100.0 & 0,211278 & 105.639 & 100.0 \\
\hline
\end{tabular}

API: active pharmaceutical ingredient; USD: United States dollar; kg: kilograms. * Standard batch (500,000 pills) with calculated yield of 98\%. 
TABLE 2

Final estimated benznidazole production costs for public and private laboratories.

\begin{tabular}{lcccc}
\hline & \multicolumn{3}{c}{$\begin{array}{c}\text { Lowest price API } \\
\text { 750USD/kg }\end{array}$} & Highest price API \\
Item & public & private & public & private \\
\cline { 2 - 5 } & 0,086278 & 0,086278 & 0,211278 & 0,211278 \\
\hline Total direct cost & 11.0 & 25.0 & 11.0 & 25.0 \\
General expenses (\%) & 14.0 & 14.0 & 14.0 & 14.0 \\
Profit (\%) & 0,1136 & 0,1280 & 0,2783 & 0,3134 \\
Price per unit* & 20,45 & 23,04 & 50,09 & 56,41 \\
Treatment per patient & & &
\end{tabular}

API: active pharmaceutical ingredient; USD: United States dollar; kg: kilograms. * Standard batch (500,000 pills) with calculated yield of 98\%.

TABLE 3

Benznidazole cost estimates versus market prices.

\begin{tabular}{|c|c|c|c|c|}
\hline Item & $\begin{array}{c}\text { Lowest price API } \\
750 \mathrm{USD} / \mathrm{kg}\end{array}$ & $\begin{array}{c}\text { Highest price API } \\
2,000 \mathrm{USD} / \mathrm{kg}\end{array}$ & Market price LAFEPE & $\begin{array}{c}\text { Market price } \\
\text { Elea Laboratory }\end{array}$ \\
\hline Pill price & 0,1280 & 0,3134 & 0,2129 & 0.4751 \\
\hline Treatment price & 23,04 & 56,41 & 38,32 & 85,52 \\
\hline
\end{tabular}

API: active pharmaceutical ingredient; USD: United States dollar; kg: kilograms; LAFEPE: Laboratório Farmacêutico de Pernambuco.

already established and it is expected that competition will stimulate a decrease in prices stipulated by the manufacturing laboratories, especially when PAHO promotes bidding for the centralized acquisition of BZN through the strategic fund.

\section{CONCLUSIONS}

Treatment for CD is a symbol of neglect to the largest and most diverse spheres regarding access to medication established by the WHO. Even after more than a hundred years since the discovery of $\mathrm{CD}$, it is still necessary to create sustainable and adequate financing and a robust agenda for investigation of new diagnostic tools and treatments.

Until the BENEFIT trial ${ }^{8}$, there has been very little evidence published from observational or small randomized trials to support the belief that treatment with effective trypanocidal drugs (nifurtimox or benznidazole) can positively affect the progression of CD in asymptomatic patients with $T$. cruzi infection or in patients with preexisting cardiac diseases. Because of the absence of more definitive, robust data, and with no other outcome trials planned for the near future, mainly owing to the lack of interest from pharmaceutical industries, doctors and their patients with chronic Chagas cardiomyopathy must use the best available information to guide their treatment decisions?

The price of the drug influences access to medication; however, the widely inadequate response to $\mathrm{CD}$ cannot be solely attributed to this factor. Nevertheless, we cannot ignore the fact that costs also deserves scrutiny and pressure in order to widen access; transparency regarding manufacturing and production is crucial in order to assure that there is no profit embedded in the production of $\mathrm{CD}$ treatment. Additionally, there is a need for competition in order to influence market regulation for the prices associated with BZN sales. When it comes to neglected diseases, patents of invention controlled through exploration monopolies are not the main obstacles for competition. However, in the case of $\mathrm{CD}$, competition requires companies to meet production quality criteria (obtain certificates from sanitary authorities), and settings accessing BZN are vulnerable to stock ruptures that partly result from problems with the production of raw materials.

We believe that urgent changes in the response to $C D$ globally require collaborative work among the various agents involved in combating the historical neglect that encompasses the disease and its affected people. It is unacceptable that the only medications for the treatment of $\mathrm{CD}$ are of high costs and thus unavailable to people infected with $\mathrm{CD}$, resulting in high social costs, suffering, disabilities, and avoidable deaths.

\section{Acknowledgments}

We thank the people that contributed to the investigations, interviews, technical visits, and questionnaires as well to the team members of MSF Brazil that supported in the collation of this review. 


\section{Conflict of interest}

The authors declare that have no conflicts of interest.

\section{Financial support}

This document is the result of the consultancy on BZN production requested by MSF Brazil. All activity costs during visits and investigations, as well as the ones derived during the writing of this report were covered by MSF.

\section{REFERENCES}

1. Chagas C. Novo Tripanozomiaze humana: estudos sobre a morfologia e o ciclo evolutivo do Schizotrypanum cruzi n. gen., n. sp., ajente etiológico de nova entidade morbida do homem. Mem Inst Oswaldo Cruz. 1909;1(2):159-218.

2. Lee BY, Bacon KM, Bottazzi ME, Hotez PJ. Global economic burden of Chagas disease: a computational simulation model. Lancet Infect Dis. 2013;13(4):342-8.

3. Pinheiro E, Vasan A, Kim JY, Lee E, Guimier JM, Perriens J. Examining the production costs of antiretroviral drugs. AIDS. 2006;20(13):1745-52.

4. World Health Organization (WHO). Fact sheet: Chagas disease (American trypanosomiasis). Washington: World Health Organization International; 2016. 166p. [updated 2016 Mar; cited 2016 Oct]. [Internet]. Available from: http://www.who.int/ mediacentre/factsheets/fs340/en/

5. World Health Organization. Chagas disease in Latin America: an epidemiological update based on 2010 estimates. Weekly Epidemiological Record (WER). 2015; 90(6):33-44. Geneva: Media Center; Feb 6 [cited 2016 Oct 13]. [Internet]. Available from: http:// www.who.int/wer/2015/wer9006.pdf

6. World Health Organization (WHO). Investing to overcome the global impact of neglected tropical diseases: third WHO report on neglected diseases. Library Cataloguing-in-Publication Data 2015. WHO. 2015;2:75-81. Mar [cited 2017 Feb 13]. [Internet]. Available from: http://apps.who.int/iris/bitstream/10665/152781/1/9789241564861_ eng.pdf?ua $=1$

7. Dias JCP, Ramos Jr AN, Gontijo ED, Luquetti A, Shikanai-Yasuda MA, Coura J, et al. II Consenso Brasileiro em Doença de Chagas,
2015. Epidemiol Serv Saúde. 2016;25(spe):7-86.

8. Rassi Jr A, Marin Neto JA, Rassi A. Chronic Chagas cardiomyopathy: a review of the main pathogenic mechanisms and the efficacy of aetiological treatment following the BENznidazole evaluation for interrupting trypanosomiasis (BENEFIT) trial. Mem Inst Oswaldo Cruz. 2017;112(3):224-35.

9. World Health Organization (WHO). Essential Medicines and Health Products. World Health Organization International; 2016. [updated 2015 Dec; cited 2016 October]. [Internet]. Available from: http:// www.who.int/medicines/areas/access/supply/en/

10. Molina I, Gómez J, Salvador F, Treviño B, Sulleiro E, Serre N, et al. Randomized trial of posaconazole and benznidazole for chronic Chagas' disease. N Engl J Med. 2014;370(20):1899-908.

11. Viotti R, Vigliano C, Lococo B, Bertocchi G, Petti M, Alvarez $\mathrm{MG}$, et al. Long term cardiac outcomes of treating chronic Chagas disease with benznidazole versus no treatment: a nonrandomized trial. Ann Intern Med. 2006;144(10):724-34.

12. Sosa-Estani S, Viotti R, Segura EL. Therapy, diagnosis and prognosis of chronic Chagas disease: insight gained in Argentina. Mem Inst Oswaldo Cruz. 2009;104(Suppl 1):167-80.

13. Garcia S, Ramos CO, Senra JF, Vilas-Boas F, Rodrigues MM, Campos-de-Carvalho AC, et al. Treatment with benznidazole during the chronic phase of experimental Chagas' disease decreases cardiac alterations. Antimicrob Agents Chemother. 2005;49(4):1521-8.

14. Sosa-Estani S, Cura E, Velazquez E, Yampotis C, Segura EL. Etiological treatment of young women infected with Trypanosoma cruzi, and prevention of congenital transmission. Rev Soc Bras Med Trop. 2009;42(5):484-7.

15. Coura J, Borges-Pereira J. Chronic phase of Chagas disease: why should it be treated? A comprehensive review. Mem Inst Oswaldo Cruz. 2011;106(6):641-5.

16. Yun O, Lima MA, Ellman T, Chambi W, Castillo S, Flevaud L, et al. Feasibility, drug safety, and effectiveness of etiological treatment programs for Chagas disease in Honduras, Guatemala, and Bolivia: 10-year experience of Médecins Sans Frontières. PLoS Negl Trop Dis. 2009;3(7):e488.

17. Marin-Neto JA, Avezum A, Sosa-Estani S, Rassi Jr A, Rosas F, et al. Randomized trial of benznidazole for chronic Chagas' cardiomyopathy. N Engl J Med. 2015;373(14):1295-306. 